\title{
Chapter 10 \\ Practical Implications: How to Deal with Structural Dilemmas?
}

\begin{abstract}
Whereas the socio-theoretical perspective on the study's key issues contributes to the academic debate, this chapter discusses some practical implications of the main findings that might be relevant not only to scholars but also to practitioners and activists in the field. First, ideas for dealing with the current challenges - present throughout Western democracies - and improving the asylum procedure are explored. I then argue for a stronger focus on procedural justice and ethical competence in public administration as a means of creating an improved asylum procedure. To that end, I discuss the issue of ethics and organizational culture and ethical decision making in the asylum procedure. The book concludes with a brief outlook on possible future research avenues.
\end{abstract}

\subsection{Envisaging Change for the Better}

At the legal and policy level, many scholars have argued that change is necessary to overcome current problems in the asylum system. Along with other scholars, Westra et al. (2015:2) argue that, for a number of different reasons, the Geneva Convention and its Protocol are "totally inadequate to deal with both the quantity and the quality of asylum seekers." Feller (2015) agrees that there are substantial arguments for rethinking the principles and concepts of the international laws regarding refugees. Numerous suggestions have been made for changes in the current legal framework at the national, supranational and international levels (Staffans 2012; Westra et al. 2015), for example, with regard to the problems of the Dublin system (Amnesty International 2010; Fratzke 2015). Gibney and Hansen (2005) propose four ideas for future directions in asylum policy in the West: (i) expanding immigration

The original version of this chapter was revised.

An erratum to this chapter can be found at https://doi.org/10.1007/978-3-319-63306-0_12

(C) The Author(s) 2018

J. Dahlvik, Inside Asylum Bureaucracy: Organizing Refugee Status

Determination in Austria, IMISCOE Research Series,

https://doi.org/10.1007/978-3-319-63306-0_10 
categories, which they regard as unlikely; (ii) focusing more on the resettlement of refugees (especially in North America); (iii) introducing asylum without welfare, that is, a market-based approach that allows for welfare incorporation only after labor market incorporation, although this would contravene most states' social protection regimes; and (iv) expanding opportunities for return, which is perceived as "morally dubious" (ibid). The status quo represents a final alternative: "perhaps the Geneva Convention is preferable to any conceivable alternative" (ibid:92). According to the authors, only a fundamental change and a substantial revision of the current asylum system would allow the deadlock to be overcome (ibid).

Nevertheless, different indicators reinforce the need to improve the current system of asylum administration in and beyond Austria. These indicators include disparities in decision making (leading to a high variance in recognition rates) and quality deficits in the procedure and decisions (including problems with fairness and equality). The works cited throughout the book, which report similar findings, illustrate that decision makers face similar challenges irrespective of different national and cultural contexts. Initially, this might be attributed to legal harmonization within the EU (CEAS); however, as we will see, even policy recommendations with regard to the adjudication of asylum in the US prove relevant to the European context. The fact that these problems exist - to a greater or lesser extent - in most Western democracies demonstrates that solutions cannot be found only at the national level. Instead, working on joint strategies for improving the procedure and learning from best practices around the world would make sense.

Ramji-Nogales et al. (2011) explain why certain approaches to reform have not been helpful thus far. The introduction of quotas, for example, would allow political influence to increase; determining and justifying the percentage for any quota would also be difficult. Additional codification is not regarded as a suitable approach either since dissent among decision makers regarding the meaning of the law is not the primary explanation for differing rates of granting asylum (Ramji-Nogales et al. 2011). Instead, as also suggested by the present study, disagreement often focuses on judgments regarding credibility. Additional regulations cannot mitigate decision makers' different approaches in trying to mold individual cases to existing legal categories or in evaluating the credibility of a claimant's assertions since these differences are seldom a consequence of the vagueness of the legal norms themselves (ibid).

However, existing problems need to be addressed. Recognition rates not only vary across regional asylum offices but also experience disparities within asylum offices; this is true at the national level (Maisch 2015) as well as at the EU level (Eurostat 2016) and in the US (Ramji-Nogales et al. 2011). Although investing in greater consistency is essential, it is likely that disparities cannot be fully eliminated due to the specific challenges of the asylum procedure (Thomas 2011a:164), as this study has shown. One approach suggested at the EU level by Amnesty International (2016) as well as by scholars and practitioners is the establishment of a supranational asylum court to create more equality. This suggestion was raised by the European Parliament in 2010, but it is currently not close to realization. At the organizational level, increasing opportunities for interaction among officers represents another approach. Ramji-Nogales et al. (2011) suggest that decision makers should receive peer-to-peer training to make disparities apparent or should sit in 
three-member panels to understand the sources of the disparities. However, the principle of multiple-assessor verification (the four eyes principle) will only be effective when taken seriously and not used as a method to share the workload, where one official only expresses her obligatory consent to her colleague's decision. ${ }^{1}$ Such enhanced interaction among colleagues might provide a remedy that would also solve difficult situations or "cases" from an ethical perspective. "The more novel and difficult the ethical choice we face, the more we need to rely on discussion and dialogue with others about the dilemma. Only by careful exploration of the problem, aided by the insights and different perspectives of others, can we make good ethical choices in such situations" (Markkula Center for Applied Ethics 2015).

In addition, in the Austrian context, deficiencies in the quality of the procedure and the decisions made on the administrative level can be seen, for example, in decisions overturned by the second instance and complaints filed with the Austrian Ombudsman Board (2017) responsible for monitoring the action of the public administration. Additionally, independent research through the UNHCR (n.d.) or the Ludwig Boltzmann Institute of Human Rights (n.d.) on the legal developments and on the authority's work reach similar conclusions. Since the long duration of the asylum procedure represents a major problem, the state's emphasis on speedy and efficient procedures works to the detriment of fairness and equality. Hence, Thomas (2011a) regards the pursuit of a quality agenda as the most promising approach. He argues that administrative justice needs to be defined not only top-down but also bottom-up; the concept refers not only to external accountability mechanisms by which individuals can challenge administrative decisions and the role of courts but also to "the mass of front-line initial decision-making and the processes necessary to ensure quality" within the procedure (Thomas 2011b:3). One possibility for providing higher standards of decision making might be to introduce adjudication at the initial decision stage through "a closer assimilation of adjudication and administration" (Thomas 2011b:292). Although certain recommendations are designed primarily for the judiciary, most of them are thus also relevant for the first instance.

Additional options for improvement include, for example, depoliticizing the institutions and placing the responsible bodies in an independent agency. Migration is increasingly constructed as a security issue (Huysmans 2006; van Munster 2009). The political process of connecting migration to criminality is related to a wider politicization in which immigrants and asylum claimants are regarded as a challenge to both the protection of national identity and welfare provisions (Huysmans 2000). Moving migration and asylum issues away from security issues and into the field of social questions - also at the institutional level - would be an important step, not only at the symbolic level. ${ }^{2}$ Regarding recruitment, it is important that the government does not use political standards when employing decision makers and that they are carefully selected according to high standards (Ramji-Nogales et al.

\footnotetext{
${ }^{1}$ At the FAO, this is usually implemented in the case of positive decisions, which have to be double-checked by the head of the unit. However, it seems essential to include negative decisions in this review process as well.

${ }^{2}$ In Austria, matters of immigration were moved from the Ministry of Social Affairs to the Ministry of the Interior at the beginning of the 1990s.
} 
2011:102). Some scholars also argue that asylum officers should have a legal education to be able to better address the complex issue (Schoenholtz et al. 2014).

In addition, developing a more professional culture and creating an authority that meets the highest standards of fairness and due process (Ramji-Nogales et al. 2011:106) could represent a viable approach to change. Increasing the number of decision makers ${ }^{3}$ and giving them enough time per case might represent another improvement for the system since "social psychology supports the idea that judges with heavy dockets are more likely to make inaccurate decisions" (ibid:108). Providing the necessary resources and periodic in-person training (as currently done by EASO) should be the norm. As the findings suggest, caseworkers constantly face situations of structural conflict that partly produce psychological stress. Since there can be fatal consequences when dissatisfaction or frustration affect the interaction with asylum claimants and the decision-making process, it is vital that the organization provides sufficient support and resources for caseworkers, such as regular supervision.

Regarding caseworkers' sources of information for decision making, regular exposure of officers and supervisors to research findings would make sense. In Germany, for example, a special newsletter (Entscheiderbrief) informs decisionmaking officials on a monthly basis by providing information on specific regions, recent case law, legal developments in Europe and other current topics, including new publications in this field. ${ }^{4}$ Such specialized, regular information would help decision makers remain up to date and gain more in-depth knowledge on current developments, ideally contributing to more carefully considered decisions. In addition, a high standard of information needs to be guaranteed, although "realistically, available country information is unlikely ever to be fully comprehensive and exhaustive" (Thomas 2011b:195).

However, to improve the situation of asylum claimants within the procedure, it is not only necessary to promote change within the institution; asylum claimants also need to be empowered by enhancing their "client autonomy" (Lipsky 2010). Respecting and encouraging asylum claimants' struggle to organize and to obtain some control over their asylum procedure requires ensuring that the procedure and its various implications are made very clear to asylum claimants. Rudimentary legal counseling through the state leaves most of the explanatory and other supportive work to NGOs. To prevent inhuman treatment and neglect of claimants' rights, it is vital to make the bureaucracy more accountable to individuals since accountability represents the link between bureaucracy and democracy (ibid:160). To empower claimants, the government could also provide appointed counsel for unrepresented applicants since "a system that claims to provide procedural due process requires

\footnotetext{
${ }^{3}$ The number of decision-making officials has increased (Bundesministerium für Inneres 2016), which can be attributed to the institutional reform in 2014 and the increase in asylum claims in 2015.

${ }^{4}$ See, for example, Entscheiderbrief 7-8/2015 (Bundesamt für Migration und Flüchtlinge 2015), http://www.bamf.de/SharedDocs/Anlagen/DE/Publikationen/Entscheiderbrief/2015/entscheiderbrief-07_08-2015.pdf?_blob=publicationFile
} 
some degree of fair representation" (Ramji-Nogales et al. 2011:113). Thomas (2011b:117) found that the presence of representation more than doubles the success rates of appeals. However, to effectively challenge the exclusionary politics of asylum, the concept needs to be re-evaluated in a more radical way, which also requires political engagement and mobilization. For a more inclusionary approach to asylum, the conception of the political subjectivity of asylum claimants must be strengthened (Squire 2009). Mountz (2010:169) emphasizes the need to think "beyond the pervasive, mythical power of the magical state" in order to imagine and strive for alternative models that "protect and include, rather than endanger and exclude."

\subsection{Procedural Justice and Ethical Competence}

The concept of procedural justice, with a focus on the treatment of asylum claimants, represents another approach for improving the quality and fairness of the procedure. Along with other scholars (Verburg and Schueler 2014; Silverman and Molnar 2015), I argue that procedural justice needs to be more vigorously pursued in the asylum procedure. As Tyler (2003) notes, the legitimacy of a justice system is more significantly shaped by public perceptions of the system's fairness than by perceptions of its effectiveness. In this sense, he makes an important distinction between an idea of justice based on process and justice based on outcome. According to Tyler, fair and respectful treatment that follows the rules - procedural justice plays a greater role for individuals than obtaining outcomes that are regarded as fair or favorable to themselves (Hough et al. 2010:205). Although this might be questioned in the context of international protection, it is still essential to consider that for a legal procedure to be viewed as fair, the quality of treatment in face-to-face encounters can be more important than the actual outcome - or at least equal to it. "Above and beyond the quality of the procedures used in the resolution of their problem, people value being treated with dignity and having their rights acknowledged" (Tyler 2003:299).

Another key element of procedural justice is the quality of decision making, as discussed above. Since decisions are generally regarded as more fair when they are made on a neutral and unbiased basis (rather than on the basis of personal views), proof of objectivity and impartiality in decision making increases perceived fairness. Administrative bodies profit from transparency since it allows them to demonstrate that decisions are made on a neutral basis (ibid:298). Tyler's findings suggest that both procedural justice and motive-based trust - the assessment of whether individuals trust the motives of the authority - influence decision acceptance and satisfaction with the decision maker. The results also highlight that the quality of interpersonal treatment and the understandability of actions are the antecedents of procedural justice and motive-based trust (ibid:300). In the context of the asylum procedure, claimants' trust in the motives of the authority is questionable, especially since those motives are not particularly transparent. Hence, this issue could be a starting point for rethinking current institutional practices and possible motivational biases. 
Beetham (1991) adds another factor to the perceived legitimacy of institutions based on the idea that institutions represent specific normative and ethical frameworks. From this perspective, legitimacy also depends on the perception that the authorities and the public share broadly similar moral positions. According to the author, such "moral alignment" - a shared sense of right and wrong - is a necessary component of legitimate authority. As Hough et al. (2010:205) note, the sense of a shared moral position is communicated to individuals by the authorities through the quality of interpersonal treatment in interactions and particularly through their procedural fairness or lack of it. The fact that the procedure is not only about acknowledging rights but also about interpersonal interaction was illustrated by the analysis of asylum interviews in Chap. 4, which highlighted the importance of the treatment of asylum claimants.

Following these observations and considering the present findings - particularly concerning the dilemma of responsibility and dissociation - I argue that the role of ethics in the administration of asylum should be strengthened. The so-called bureaucratic ethos (du Gay 2000) does not seem to sufficiently secure justice through rational, rule-based assessment and the principle of equal treatment. The structural dilemmas that officials face in deciding upon asylum claims are reinforced since administrators act in an (ethically) difficult environment. "Given the ambiguities of ethical principles and the role of competing values in giving them meaning within particular contexts, ethical practice comes down to a personal responsibility for weighing and balancing conflicting imperatives" (Pratchett 2000:122). The strategy of focusing on ethics in decision makers' everyday work is relatively independent of the diverse developments of the political and legal framework since the process of deciding on an asylum claim is inherently difficult. According to Martinez (2009:74), understanding administrators as "moral agents" can be regarded as "a starting point for improving ethics."

A capacity-building approach that includes the development of caseworkers' ethical competence (Geuras and Garofalo 2011; Sedlačko and Dahlvik 2017) could support decision makers in dealing with the uncertainties and ambiguities inherent in deciding asylum claims. While bearing in mind that refugee status determination is a legal (human rights) issue, a focus on ethical decision making may not only help advance the understanding of asylum claimants' situations and promote their recognition as individuals but also give the ruling principles of equality and nondiscrimination more importance in officials' discretionary power. An invitation to decision makers to imaginatively identify with the claimants, as proposed by Morris (2010:143), can, for example, contribute to mitigating simplifications and thoughtless categorization in this "people-processing bureaucracy" (Lipsky 2010). Competence-building - including ethical competence - and awareness-raising can contribute to improving the quality of the asylum administration by modifying entrenched routines. However, the issue is also relevant at a broader level. As Juss (2006:ix) argues in the context of migration and global justice, "never in recent times has there been a situation in the democratic world that has more urgently needed brave moral leadership." 
In addition, it would make sense to include human rights more prominently in the relevant curriculums. Whereas philosophy alone cannot provide the relevant tools, it is also insufficient to examine social equity only within the confines of policymaking. Therefore, Alvez and Timney (2008:51) suggest using human rights theory as a means to incorporate social equity into the public administration curriculum since "advancing social equity is, or should be, a primary focus of public administrators."

\subsubsection{Ethics and Organizational Culture in Public Administration}

Similar to immigration policies and laws embedded in national traditions (Bauböck 1999; Morris 2002; Zincone et al. 2011), the practices of administrators are shaped by organizational culture. Previous research has shown that immigration departments and caseworkers' practices are influenced by wider politics as well as by organizational cultures (Psimmenos and Kassimati 2003; Triandafyllidou 2003). Supranational training on the EU level, such as the training provided by the EASO, may represent a step toward harmonization, but it will always be confronted by socio-political and cultural heritage as well as organizational cultures that are difficult to change since they have grown over time and practices are deeply rooted within them.

To do their job, officials need to know not only the legal framework but also the organizational culture and their own role within it since this culture has an impact on every action of the organization (Martinez 2009). Organizational culture can be defined "as the visible organizational elements, values and hidden assumptions that provide rules of behavior for [the organization's] members," whereas the consensus on these elements connects the organizational members (Erakovich and Wyman 2009:80). Ideology and values are thus represented through organizational culture. According to Erakovich and Wyman (2009:82), the ethics of an organization amount to the shared behavior, which guides the ethical actions and decisions of its members. Since these shared practices influence officials in the decision-making process, the authors argue that organizational culture is predictive of ethical behavior.

Turning to the specific context of public administration, ethical issues can be understood as a mosaic of individual motives, the organization's mandates, and societal values (Lawton and Macaulay 2009). To take ethical practices seriously, an organization must enable and promote ethical behavior, and its members, at all levels of the hierarchy, must comprehend the need for ethical behavior (Martinez 2009). The aim should thus be "to ensure that ethical behaviour is an integral part of the whole" (ibid:73). Therefore, the question of ethics in public administration is also related to the strength of prevailing organizational and individual ideologies vis-à-vis the legal framework. 
The findings demonstrate that the "ethical dilemmas of immigration policy" (Zolberg 2012) are also observable at the level of everyday practices in organizations. Civil servants make value-based judgments on what is true or false, right or wrong, good or bad, and they express feelings such as empathy or suspicion, pity or outrage. The asymmetrical relationship between the administrator and the claimant, between those who possess power and resources and those who depend on these resources, reinforces the strength of these values and feelings (Fassin 2015). What these agents think and do is also related to and reflects public and political discourses and actions, such as the stigmatization or criminalization of asylum claimants. As Morris (2010:131) notes, "answers given by courts are functions of a larger social and political debate"; to some extent, this also seems to be valid for decisions made by the administration. These "various forms of moral mobilization" (ibid: 256) give rise to the tensions, conflicts and dilemmas that require caseworkers' action in everyday work.

To take into account the tensions at the heart of the state between the coherences and contradictions, between over-determination of the action and the indetermination of the agents, between the macro-power of the law and policy makers and the micro-powers of the agents in the institutions is to implement what Michel Foucault called a "critical morality" (ibid:259).

To capture the moral dimension of state institutions, Fassin (2015) engages two concepts, moral economies and moral subjectivities, combining "the two major approaches to moral questions in the social sciences inspired by Kant and Aristotle, namely, the ethic of duty and the ethic of virtue, respectively" (Fassin 2015:10). Both ethics are combined in the everyday work of public administrations that have to address social issues and respond to concrete situations. The relevance of officials' responses given in these situations emphasizes the role of evaluations and emotions in the bureaucratic encounter, as discussed above. Additionally, both moral economies and subjectivities have underlying political stakes. The moral work of institutions thus consists of dealing with the tensions within the general public sphere regarding the issue at hand (moral economies) as well as dealing with the dilemmas administrators face in trying to resolve these problems (moral subjectivities) (ibid). Moral economies refer to the judgments and feelings that characterize the collective understanding of a problem at a specific time and place in history. "Thus, one can speak of the moral economy of asylum to characterize the transformations of values and affects around the question of refugees" (ibid:9). Originally positively valued and emotionally charged, refugees were perceived as victims or heroes; over time, their image transformed into that of the "fake refugee," stirring mistrust largely regardless of where and what the person was escaping (ibid).

Whereas moral economies concern social facts, moral subjectivities "refer to the processes by which individuals develop ethical practices in their relationships with themselves or others" (ibid).

[Moral subjectivities] attest to the autonomy and freedom of agents, notably within contexts in which opposing values can come into conflict, contradictory sentiments can create tensions, or political injunctions can run counter to professional ethos. They may be conscious exercises stemming from reflections on a dilemma, or they may be ordinary gestures stemming from a sense of care (ibid). 
Considering the findings of this study, I argue that it is important to increasingly focus on ethics in public administration - in research as well as in practice - especially in the field of asylum and in decisions makers' everyday work, which is characterized by several dilemmas.

\subsubsection{Ethical Decision Making in the Asylum Procedure}

Ethical questions are ubiquitous. They become relevant in different contexts: in "acting ethically as individuals, creating ethical organizations and governments, and making our society as a whole ethical in the way it treats everyone" (Markkula Center for Applied Ethics 2015). Since public administration is never an end in itself but always serves the aims of the context in which it is embedded, administrators are confronted with a variety of objectives that cannot always be reconciled (Banke and Thedieck 2011). Dilemmatic situations such as those explored in this study are predetermined; this also includes tensions between legal provisions and the individual sense of justice. Dilemmas can arise when the ethical evaluation of a situation differs from the evaluation that is prescribed by the required application of law. Banke and Thedieck (2011) illustrate the situation of a decision maker with a table of four quadrants considering the legal and ethical aspects of social action. Officials deciding upon asylum claims might thus be confronted with situations in which legal or administrative norms and the individual's sense of justice or ethic responsibility do not coincide but collide. We also need to be aware that the purpose of asylum is to protect individuals from serious harm and not to select morally desirable individuals for membership in our polity (Souter 2011).

How should decisions be made in this imbroglio? "Making good ethical decisions requires a trained sensitivity to ethical issues and a practiced method for exploring the ethical aspects of a decision and weighing the considerations that should impact our choice of a course of action" (Markkula Center for Applied Ethics 2015). Hence, focusing on a capacity-building approach that includes the development of public officials' ethical competence seems to be a desirable advancement (Geuras and Garofalo 2011). However, in addition to the philosophical problems, it is a difficult task to develop "a workable model for administrative ethics [since] the field of public administration is extremely diverse and exists at all levels of government" (Martinez 2009:102). It may thus be "unethical" (Pratchett 2000) to apply one standard code of ethics irrespective of the specific context. Nonetheless, public officials might be supported in ethical decision making in all fields of public administration, including in the asylum bureaucracy.

The Markkula Center for Applied Ethics at Santa Clara University (2015) has developed a framework for ethical decision making that can also be applied in the context of public administration. ${ }^{5}$ It includes five phases: (a) recognizing an ethical

\footnotetext{
${ }^{5}$ The Center has also developed an app for making ethical decisions, "a practical tool for thinking through tough decisions," available at https://itunes.apple.com/us/app/ethical-decision-making/ id799710217? mt=8, accessed 27 February 2017.
} 
issue, (b) getting the facts, (c) evaluating alternative actions, (d) making a decision and testing it, and (e) acting and reflecting on the outcome. This method can help to explore ethical dilemmas and identify ethical courses of action. However, the findings show that the processes of obtaining the facts and evaluating alternative actions (b and c) are already highly problematic in the context of administering asylum claims. In the search for facts, caseworkers engage in construction practices characterized by the fact that an official's "perception apparatus will partially screen out data adverse to his interests and magnify those favoring his interests" (Downs 1967:180). In addition to these challenges in dealing with asylum claims, the findings suggest that the tasks of recognizing an ethical issue and reflecting on the outcome (a and e) especially need to be encouraged and stimulated in the asylum administration. As we have seen, officials often try to "escape personal responsibility because they [are] part of a larger organization" (Martinez 2009:85). While it is easier to blame others when something goes wrong, it is crucial that decision makers assume personal responsibility and do not dismiss ethical questions.

Geuras and Garofalo (2011:391) note that ethical change, similar to other substantive reforms, is generally perceived as disruptive and as offering only uncertain long-time benefits at (potentially high) immediate costs. By contrast, compliance is comforting and comfortable for administrators. However, to eliminate compliance and moral neutrality, the understanding of the nature of public service and of the public servant's responsibilities needs to change. Decision-making officials ought to be conceived and conceive themselves as competent moral agents instead of obedient bureaucrats. Disincentives with regard to ethical development are powerful and pervasive in the public sector, and recommendations on this level can only be realized in the scope of reframing public service ethics (ibid). This scope would include "a reinvigorated conception of ethical public administrators, their obligation to resolve ethical dilemmas, and their covenant with the public, not as experts but as citizens in league with their fellow citizens" (Garofalo 2008:351 in Geuras and Garofalo 2011:391) or future fellow citizens.

Analyzing the drivers of administrative reform in the US and Scandinavia, Wise (2002) finds that past reforms of the public service sector have been driven not only by economic and rational forces but also by demands for greater social equity, democratization, empowerment and the humanization of public administration. This perspective offers hope that change in this direction may also be realized in the future in Austria and other European public administrations, including asylum administrations. According to Morris (2010:131), judgment "can be a source of social change, opening up new areas of interpretation and application for human rights, as in the extension of the ECHR to address social as well as civil and political rights" - also in the field of asylum. While this might be particularly true for courts, it is also valid for the administration to some degree. Every agent can contribute to change; every member of the organization is therefore responsible for improving the ethical organizational culture on a day-by-day, decision-by-decision basis. Structuration theory suggests that the system is part of the problem, but it is not the 
entire problem: "A system is what its members make it" (Sheeran 1993:150). It is crucial to build on human agency and the power of individuals to induce change through social action.

Clearly, in the public sector, organizational structure, culture, and formal rules play an important part in determining the choices that are made, but ultimately, the individual must make the choice. An ethical system can never work if it fails to assign final responsibility to the individual (Martinez 2009:97).

At the same time, we need to bear in mind that "the nature and extent of the administrator's role will determine the nature and extent of that personal responsibility" (ibid:119). Eventually, the greatest burden rests on the highest-ranking members of the organization since they set the tone for the entire agency, thereby making it easier or harder for the others to achieve improvement (Geuras and Garofalo 2011). Therefore, future studies might also explore new avenues by studying (the potentials of) change and resistance from inside state action in migration and asylum regimes.

\subsection{Future Avenues}

The findings from this research suggest that studying certain aspects of this specific public administration in more detail would be interesting. In particular, the issue of emotions in public administration represents an intriguing subject. Emotions seem to play a vital role in situations in which individuals have the power to decide on the future lives of others. The topic is also interesting with regard to the treatment of claimants and interpersonal interaction as elements of procedural justice. In this context, the role of ethics in public administration also needs to be investigated further, not only theoretically but also with a focus on practical implementation. Research on public administration in general is more developed in other countries, such as France or the US; this is particularly true for research in the field of ethics in public administration, which is only now emerging in the German-speaking world. "We must also consider the consequences of what the state and its agents do" (Fassin 2015:260), especially in the domains of injustice and inequality.

Referring to the local context of this study, the German-speaking scientific community has generally paid too little attention in the past to socio-legal issues or studies on law and society, including the role of state institutions. With regard to the more recent developments in the field of asylum in Austria, including organizational change and the introduction of a uniform training course, it would be worthwhile to develop a follow-up study on the new Federal Office for Immigration and Asylum as well as in-depth comparative research. In general, viewing public authorities as observation posts for the relation between the citizen and the state represents a particularly attractive approach. 


\section{References}

Alvez, J. D. S., \& Timney, M. (2008). Human rights theory as a means for incorporating social equity into the public administration curriculum. Journal of Public Affairs Education, 14(1), 51-66.

Amnesty International. (2010). The Dublin II trap: Transfers of asylum-seekers to Greece. London: Amnesty International Publications. Retrieved from www.amnesty.org/en/library/ info/EUR25/001/2010

Amnesty International. (2016). Amnesty international report 2015/16. The state of the world's human rights. Retrieved from https://www.amnesty.org/en/latest/research/2016/02/ annual-report-201516

Austrian Ombudsman Board. (2017). Missstandsfestellungen und Veranlassungen der Volksanwaltschaft. Austrian Ombudsman Board. Retrieved from http://volksanwaltschaft.gv.at/downloads/8174/Missstandfeststellungen_der_Volksanwaltschaft_-_ Bundesverwaltung_-_2017.pdf

Banke, B., \& Thedieck, F. (2011). 'Verwaltungsethik'. In J. Kegelmann, G. Stephan, \& E. Meurer (Eds.), Rechnungswesen und Controlling in der Öffentlichen Verwaltung (pp. 455472). Freiburg: Haufe. Retrieved from http://www.verwaltungmodern.de/wp-content/ uploads/2011/12/Thedieck_Banke_Verwaltungsethik.pdf

Bauböck, R. (1999). Immigration control without integration policy - an Austrian dilemma. In G. Brochmann \& T. Hammar (Eds.), Mechanisms of immigration control: A comparative analysis of European regulation policies (pp. 97-134). Oxford/New York: Berg.

Beetham, D. (1991). The legitimation of power. Basingstoke: Macmillan.

Bundesministerium für Inneres. (2016). Jahresbilanz 2015. Retrieved from http://www.bfa.gv.at/ files/Statistiken/BFA_Jahresbilanz2015_web.pdf

Downs, A. (1967). Inside bureaucracy. Boston: Little, Brown.

du Gay, P. (2000). In praise of Bureaucracy: Weber - organization - ethics. London/Thousand Oaks: Sage.

Erakovich, R., \& Wyman, S. (2009). Implications of organizational influence on ethical behavior. In R. W. Cox (Ed.), Ethics and integrity in public administration: Concepts and cases (pp. 77-91). Armonk: M.E. Sharpe.

Eurostat. (2016). Asylum decisions in the EU. Retrieved from http://ec.europa.eu/eurostat/doc uments/2995521/7233417/3-20042016-AP-EN.pdf/34c4f5af-eb93-4ecd-984c-577a5271c8c5

Fassin, D. (2015). At the heart of the state: The moral world of institutions. London: Pluto Press.

Feller, E. (2015). Foreword. In S. S. Juss, T. Scovazzi, \& L. Westra (Eds.), Towards a refugee oriented right of asylum (pp. vii-vix). Farnham/Surrey/Burlington: Ashgate.

Fratzke, S. (2015). Not adding up: The fading promise of Europe's Dublin system. Brussels: Migration Policy Institute Europe. Retrieved from http://www.migrationpolicy.org/sites/ default/files/publications/MPIe-Asylum-DublinReg.pdf

Geuras, D., \& Garofalo, C. (2011). Practical ethics in public administration. Vienna: Management Concepts, London.

Gibney, M. J., \& Hansen, R. (2005). Asylum policy in the west: Past trends, future possibilities. In G. J. Borjas \& Jeff Crisp (Eds.), Poverty, international migration and asylum (pp. 70-96). Basingstoke: Palgrave Macmillan.

Hough, M., Jackson, J., Bradford, B., Myhill, A., \& Quinton, P. (2010). Procedural justice, trust, and institutional legitimacy. Policing: A Journal of Policy and Practice, 4(3), 203-210. https:// doi.org/10.1093/police/paq027.

Huysmans, J. (2000). The European Union and the securitization of migration. JCMS: Journal of Common Market Studies, 38(5), 751-777. https://doi.org/10.1111/1468-5965.00263.

Huysmans, J. (2006). The politics of insecurity. Fear, migration and asylum in the EU. London: Routledge.

Juss, S. S. (2006). International migration and global justice. Aldershot: Ashgate. 
Lawton, A., \& Macaulay, M. (2009). Ethics management and ethical management. In R. W. Cox (Ed.), Ethics and integrity in public administration: Concepts and cases (pp. 107-120). Armonk: M.E. Sharpe.

Lipsky, M. (2010). Streel-level bureaucracy: Dilemmas of the individual in public services (30th anniversary expanded). New York: Russell Sage Foundation.

Ludwig Boltzmann Institute Human Rights. (n.d.). Pilot project on quality assurance for first instance asylum proceedings in Austria. Retrieved from http://bim.lbg.ac.at/en/ pilot-project-quality-assurance-first-instance-asylum-proceedings-austria

Maisch, A. (2015, January 17). So unterschiedlich bewerten die Länder Asylanträge. Welt Online. Retrieved from http://www.welt.de/politik/deutschland/article136479315/So-unterschiedlichbewerten-die-Laender-Asylantraege.html

Markkula Center for Applied Ethics (2015). A framework for ethical decision making. Retrieved from https://www.scu.edu/ethics/ethics-resources/ethical-decision-making /a-framework-for-ethical-decision-making

Martinez, J. M. (2009). Public administration ethics for the 21st century. Santa Barbara: Praeger.

Morris, L. (2002). Managing migration: Civic stratification and migrants' rights. Abingdon: Psychology Press.

Morris, L. (2010). Asylum, welfare and the cosmopolitan ideal. A sociology of rights. Abingdon: Routledge.

Mountz, A. (2010). Seeking asylum: Human smuggling and bureaucracy at the border. Minneapolis: University Of Minnesota Press.

Pratchett, L. (2000). The inherently unethical nature of public service ethics. In R. A. Chapman (Ed.), Ethics in public service for the new millennium (pp. 111-126). Aldershot/Burlington: Ashgate.

Psimmenos, I., \& Kassimati, K. (2003). Immigration control pathways: Organisational culture and work values of Greek welfare officers. Journal of Ethnic and Migration Studies, 29(2), 337-371. https://doi.org/10.1080/1369183032000079639.

Ramji-Nogales, J., Schoenholtz, A. I., \& Schrag, P. G. (2011). Refugee roulette: Disparities in asylum adjudication and proposals for reform. New York: New York University Press.

Schoenholtz, A. I., Schrag, P. G., \& Ramji-Nogales, J. (2014). Lives in the balance: Asylum adjudication by the department of homeland security. New York: New York University Press.

Sedlačko, M., \& Dahlvik, J. (2017). Learning with a 'scientific temper': Training civil servants for transformative practice. Paper for the Copenhagen Forum Annual Workshop 2016, 9-11 November 2016, Rotterdam, NL.

Sheeran, P. J. (1993). Ethics in public administration: A philosophical approach. Westport: Greenwood Publishing Group.

Silverman, S. J., \& Molnar, P. (2015). Unshackled discretion: Barriers to procedural justice in the Canadian immigration detention system. Detention and asylum research cluster working paper no. 1. Retrieved from https://www.academia.edu/11993530/Unshackled_Discretion_Barriers_ to_Procedural_Justice_in_the_Canadian_Immigration_Detention_System

Souter, J. (2011). "Bogus" asylum seekers? The ethics of truth-telling in the asylum system'. openDemocracy, July 29. Retrieved from http://www.opendemocracy.net/5050/james-souter/ bogus-asylum-seekers-ethics-of-truth-telling-in-asylum-system

Squire, V. (2009). The exclusionary politics of asylum. Houndmills/Basingstoke: Palgrave Macmillan.

Staffans, I. (2012). Evidence in European asylum procedures. Leiden: Martinus Nijhoff Publishers.

Thomas, R. (2011a). Refugee roulette. A UK perspective. In J. Ramji-Nogales, A. I. Schoenholtz, \& P. G. Schrag (Eds.), Refugee roulette: Disparities in asylum adjudication and proposals for reform (pp. 164-186). New York: New York University Press.

Thomas, R. (2011b). Administrative justice and asylum appeals: A study of tribunal adjudication. Oxford: Hart. 
Triandafyllidou, A. (2003). Immigration policy implementation in Italy: Organisational culture, identity processes and labour market control. Journal of Ethnic and Migration Studies, 29(2), 257-297. https://doi.org/10.1080/1369183032000079611.

Tyler, T. R. (2003). Procedural justice, legitimacy, and the effective rule of law. Crime and Justice, 30, 283-357.

UN High Commissioner for Refugees (UNHCR). (n.d.). Aufgaben von UNHCR in Österreich. Retrieved from http://www.unhcr.at/unhcr/in-oesterreich.html

van Munster, R. (2009). Securitizing immigration: The politics of risk in the EU. Basingstoke: Palgrave Macmillan UK.

Verburg, A., \& Schueler, B. (2014). Procedural justice in Dutch administrative court proceedings. Utrecht Law Review, 10(4), 56-72.

Westra, L., Juss, S. S., \& Scovazzi, T. (2015). Introduction to the question of asylum seekers: "Se non Ora, Quando?". In L. Westra, S. S. Juss, \& T. Scovazzi (Eds.), Towards a refugee oriented right of asylum (pp. 1-9). Farnham/Surrey/Burlington: Ashgate.

Wise, L. R. (2002). Public management reform: Competing drivers of change. Public Administration Review, 62(5), 556-567. https://doi.org/10.1111/1540-6210.00237.

Zincone, G., Pennix, R., \& Borkert, M. (Eds.). (2011). Migration policymaking in Europe: The dynamics of actors and contexts in past and present. Amsterdam: Amsterdam University Press.

Zolberg, A. R. (2012). Why not the whole world? Ethical dilemmas of immigration policy. American Behavioral Scientist, 56(9), 1204-1222. https://doi.org/10.1177/0002764212443821.

Open Access This chapter is licensed under the terms of the Creative Commons Attribution 4.0 International License (http://creativecommons.org/licenses/by/4.0/), which permits use, sharing, adaptation, distribution and reproduction in any medium or format, as long as you give appropriate credit to the original author(s) and the source, provide a link to the Creative Commons license and indicate if changes were made.

The images or other third party material in this chapter are included in the chapter's Creative Commons license, unless indicated otherwise in a credit line to the material. If material is not included in the chapter's Creative Commons license and your intended use is not permitted by statutory regulation or exceeds the permitted use, you will need to obtain permission directly from the copyright holder.

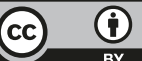

